\title{
Leyendo una Currícula de Ciencias Naturales en un Abordaje Freiriano: el Caso de los Diseños Curriculares de la Provincia de Buenos Aires, Argentina
}

Lendo um Currículo de Ciências Naturais em Abordagem Freiriana: o Caso dos Desenhos Curriculares na Província de Buenos Aires, Argentina

Reading a Natural Sciences Curriculum with a Freirian Approach: the Case of Curricular Designs in the Province of Buenos Aires, Argentina

\author{
(10) Alejandra E. Defago, ${ }^{(1)}$ Raúl Esteban Ithuralde
}

Palabras clave Resumen La provincia de Buenos Aires sancionó sus Diseños Educación en Curriculares para la Educación Secundaria Orientada entre los Ciencias Naturales; años 2010 y 2012. En estos se sostiene que para la Educación en Educación Popular;

Comunidad de Aprendizaje; Curriculum; Paulo Freire. Ciencias Naturales que ésta tiene como objetivo la formación para la participación ciudadana y que las Ciencias son actividades sociales y humanas situadas histórica y culturalmente. Estas definiciones dejan el camino abierto para que, en las aulas, se puedan desarrollar prácticas que se acerquen progresivamente a la Educación Popular en esta área. En este trabajo presentamos los resultados de observaciones de clases de Ciencias Naturales que reconocemos que trabajan en perspectiva freiriana, identificando elementos clave necesarios para esta integración. Hallamos que las estrategias privilegiadas para interpretar los Diseños Curriculares en un abordaje emancipatorio son: el llevar adelante una educación situada, recuperando problemáticas de los grupos sociales que asisten a la escuela y pensada desde la justicia curricular, y el construir vínculos con la comunidad. 
Palavras-chave Resumo A província de Buenos Aires sancionou seus Projetos Educação em Curriculares de Educação Secundária Orientada entre 2010 e 2012. Ciências Naturais; Nestes, argumenta-se que a Educação em Ciências Naturais visa a Educação Popular; formação para a participação cidadã e a Ciência é uma atividade Comunidade de social e humana situada histórica e culturalmente. Essas definições Aprendizagem; abrem caminho para que, na sala de aula, desenvolvam-se práticas Currículo; que se aproximem progressivamente da Educação Popular nessa Paulo Freire. área. Neste trabalho, apresentamos os resultados das observações das aulas de Ciências Naturais que reconhecemos que trabalham na perspectiva Freiriana, identificando os elementos-chave necessários para esta integração. Sinalizamos que as estratégias privilegiadas para interpretar os Desenhos Curriculares em uma abordagem emancipatória são: fazer uma educação situada, resgatar problemas dos grupos sociais que frequentam a escola, pensar a partir da justiça curricular e construir vínculos com a comunidade.

Keywords Abstract The province of Buenos Aires issued Curricular Designs Natural Science (guidelines) for Oriented Secondary Education between 2010 and Education; 2012. They argue that Natural Sciences Education should train for Popular Education; citizenship, and that Sciences are social and human activities situated Learning historically and culturally. These definitions open the door so that Community; practices that approach Popular Education progressively can be Curriculum; developed in the classroom. In this paper we present results from Paulo Freire. observations of Natural Sciences classes that we identify as using a Freirean perspective, describing key elements necessary for this integration. We found that the best strategies to interpret Curriculum Designs from an emancipatory perspective are: carrying out a situated education, assessing social issues of the groups that attend school, and thinking the curriculum from a justice point of view, and creating bonds with the community. 
"en el nivel de una posición crítica que no opone el saber del sentido común a otro saber más sistemático o de mayor exactitud, sino que busca una síntesis de los contrarios, el acto de estudiar implica al de leer, aunque no se agote en éste. De leer el mundo, de leer la palabra y así leer la lectura del mundo hecha anteriormente."

Cartas a quien pretende enseñar (Freire, 2014a, p. 47)

\section{Introducción}

Se cumplen 100 años del nacimiento de Paulo Freire y se han cumplido más de 60 años de su primer escrito Educación y Actualidad Brasilera (Freire, 1959), producido para su examen de cátedra en Recife, a partir de reflexiones sobre su trabajo en alfabetización. En este libro el maestro Paulo ya aborda temáticas que serán el eje de su construcción teórica a lo largo de su extensa carrera: el diálogo, la violencia como mecanismo de introyectar al colonizador, la necesidad de emancipación. Paulo Freire insistirá a lo largo de toda su actividad en el carácter político de la educación. A partir de este posicionamiento, considera que las educadoras y los educadores toman, necesariamente, sea de manera implícita o explícita, una posición frente a la realidad. Esa posición puede reforzar la opresión o producirse en un sentido emancipatorio.

En este trabajo exploramos posibles ejes, a partir de los cuales es posible pensar la práctica docente en las materias del área de Ciencias Naturales, desde una concepción de educación popular de orientación freiriana. En tal sentido, creemos que, el énfasis está puesto en dos grandes nudos de su producción: la interpretación situada del curriculum con eje en la justicia curricular.

En Argentina, los Diseños Curriculares son producidos por cada jurisdicción (provincias y la ciudad autónoma de Buenos Aires) en base a lineamientos acordados a nivel federal entre las 24 jurisdicciones en que está organizado el sistema educativo y el gobierno nacional. Esos lineamientos surgen del acuerdo de todas las jurisdicciones a través de diversos mecanismos de consulta y en relación con el legado a transmitir a las generaciones jóvenes. En particular en la provincia de Buenos Aires, que fue la primera en establecer los acuerdos luego de la sanción de la Ley de Educación Nacional N²6.206 en 2006, se llevaron adelante diversas acciones para relevar las necesidades educativas de los adolescentes y jóvenes bonaerenses, así como las opiniones de los docentes, los gremios y los diversos actores que forman parte de la comunidad educativa. El trayecto recorrido desde el inicio a la finalización de este proceso llevó más de cinco años e implicó una gran transformación de la escolaridad secundaria de la provincia, sus prácticas, sus contenidos y la concepción misma de este tramo educativo que pasó de ser optativo a ser obligatorio. La obligatoriedad de estos 6 años de trayecto formativo requería un posicionamiento muy claro en relación con la inclusión de las y los adolescentes y jóvenes que debieran transitarlo. La concepción del estudiante como sujeto de derecho fue uno de los pilares en este camino. Desde esta concepción inclusiva y democratizadora se inició el proceso de consulta, discusión y escritura de los diseños curriculares para todas las materias y todos los años de la escuela secundaria. Consecuente con este posicionamiento, se conciben 
los contenidos a incluir como aquellos que sean "socialmente productivos, políticamente emancipadores y culturalmente inclusivos". (Cullén, 2009, p. 120) y al curriculum como "síntesis de elementos culturales (conocimientos, valores, costumbres, creencias, hábitos) que conforman una propuesta político-educativa pensada e impulsada por diversos grupos y sectores sociales cuyos intereses son diversos y contradictorios" (De Alba, 1998, p.59), destacado en original). Con estos lineamientos, se definen los fines de la educación secundaria que se resumen, de acuerdo con lo planteado en el Marco General de los diseños curriculares para la Educación Secundaria Orientada (DGCyE, 2010a), en:

- ofrecer situaciones y experiencias que permitan a los estudiantes la adquisición de saberes para continuar sus estudios;

- fortalecer la formación de ciudadanos y ciudadanas para el ejercicio de una ciudadanía activa en pos de la consolidación de la democracia;

- vincular la escuela y el mundo del trabajo a través de una inclusión crítica y transformadora de los estudiantes en el ámbito productivo.

Desde este marco conceptual se produjeron los diseños curriculares de todas las orientaciones de la escuela secundaria. En este trabajo, tomaremos el caso de los Diseños Curriculares de Química y de Ambiente que produjimos desde la Dirección General de Cultura y Educación (DGCyE) de la provincia de Buenos Aires para la Educación Secundaria Orientada en Ciencias Naturales entre los años 2009 y 2012 (DGCyE, 2010b, 2011 y 2012; Defago \& Ithuralde, 2018a y 2018b). Estos diseños se basan en la perspectiva de Alfabetización Científica y Tecnológica (Fourez, 1997), teniendo como objetivo la formación de una ciudadanía activa en la toma de decisiones para la transformación de la realidad. Retoma también la noción de Ciencia Escolar en tanto propone:

establecer en el interior de las instituciones en las que cobre vida, una comunidad de aprendizaje, en la que los y las estudiantes tengan la oportunidad de construir, desde sus saberes, las concepciones que dan cuenta de los fenómenos naturales y tecnológicos acorde con los modelos científicos actuales y a la vez accesibles a su comprensión. Sin embargo, es preciso aclarar que la ciencia escolar no es la ciencia de los científicos, sino una versión elaborada para su aprendizaje en los ámbitos escolares" (DGCyE, 2010b, p. 17).

La ciencia escolar, tal como se la concibe en estos diseños, no es una transposición directa de las disciplinas, en tanto se estructura en función de los intereses del estudiantado (abarcando incluso contenidos que no necesariamente han sido trabajados por la ciencia académica), promoviendo así una reflexión sobre contenidos escolares (Izquierdo Aymerich, 2005; Terigi, 1999). Estos abarcan a "los contenidos axiológicos -valores culturales y sociales- como las actitudes, sentimientos y emociones, ya que las decisiones personales y grupales sobre las cuestiones científico-tecnológicas están atravesadas por estos aspectos" (DGCyE, 2010b, p. 11). Así, la "ciencia escolar, en esta perspectiva, es discursiva, proporciona autonomía, es autónoma, es aplicada, es diversa y es rigurosa (Defago \& Ithuralde, 2018a, p. 1203-3). 
De igual modo, en estos diseños curriculares, se apela a la vez a ciertas estrategias privilegiadas, a partir de una relectura de la teoría SocioHistórica de Lev Vigotsky, como ser: el Hablar, Leer y Escribir en Ciencias; la utilización de modelos; el trabajo con problemáticas y la contextualización de los contenidos disciplinares.

Entendemos que el curriculum es una propuesta político-educativa y una síntesis de elementos culturales que expresa una relación de fuerzas entre distintos grupos sociales y a la vez es objeto de fuertes disputas por la hegemonía, e implica entonces un arbitrario cultural (de Alba, 1998). En su producción entonces se expresan contradicciones, en las que se yuxtaponen elementos impuestos por grupos sociales hegemónicos con otros (los menos) de grupos sociales subalternos, con intereses mayormente antagónicos entre sí. Este proceso de construcción curricular implica un contacto cultural que "históricamente ha sido conflictivo, desigual y productivo" (de Alba, 1998, p. 65). Consideramos al curriculum producido como parte fundamental de la política educativa construida desde el Estado. Y, al mismo tiempo, entendemos al Estado como campo de disputa y como actor preponderante en la construcción de racionalidades del modelo educativo (Torres \& Schugurensky, 1993).

Suscribimos en este trabajo a la la hipótesis de especificación curricular formulada por Flavia Terigi (1999), quien sostiene que el curriculum es reinterpretado y transformado en diferentes niveles, desde los más centrales en la producción de los documentos de política educativa que hacen de guía a los diseños hasta su nivel más concreto en el cual ciertos contenidos son enseñados y evaluados por personal docente en las escuelas. La resignificación sucesiva del curriculum por parte de agentes educativos no elimina sus efectos sociales. Como mencionábamos, en el proceso de producción del curriculum existen actos de institución como parte de luchas por la clasificación social de agentes, por cómo se representará a distintas/os actores sociales. En estos procesos, los capitales acumulados por cada sector en disputa se ponen en juego, mostrando la dispar capacidad para dar legitimación a los elementos culturales de cada grupo (Bourdieu, 2012). En este sentido, no es probable que dentro de un Estado capitalista se puedan oficializar diseños curriculares que apuesten de lleno por la emancipación de los sectores oprimidos tal como lo plantea Paulo Freire (2010, 2014b). Dicha opción necesitaría de una fuerza social de la cual no disponen dichos sectores, justamente por ser grupos subalternizados. Sin embargo, las escuelas pueden ser, a la vez que espacios de construcción de la hegemonía, instituciones en las cuales se recrean prácticas de resistencia y/o contrahegemonía (Ezpeleta \& Rockwell, 1982). Del mismo modo, es fácil reconocer en ellas, la diversidad en múltiples aspectos. Así expresado, acordamos con la analogía de Pierre Bourdieu (2014) al imaginarse al Estado como un caleidoscopio (Bourdieu, 2014), poseedor de múltiples y variadas facetas y formatos de intervención. De esta forma, los mencionados diseños curriculares son portadores de claves propias de la educación Popular posibilitando a las/os docentes, en los niveles más concretos del proceso de especificación curricular, desarrollar prácticas desde esta perspectiva. En este sentido, recuperamos la experiencia de Paulo Freire como secretario de Educación 
de la ciudad de San Pablo entre los años 1990 y 1992 (Freire, 2010b, 2014a). Entendemos que esta alternativa es posible en tanto los docentes pueden hacer uso de su autonomía relativa en su denominado trabajo vivo en acto (Franco \& Merhy, 2021), en su labor diaria y en cada acto educativo. En estos actos se juega entonces el sentido emancipador de las prácticas docentes concretas. En muchos casos, esta perspectiva hacia la educación popular implica que los/as docentes construyan vínculos con movimientos sociales, organizaciones o comunidades organizadas más amplias que la escolar, desarrollando desde allí prácticas pedagógicas emancipadoras coordinadas junto con estos colectivos, y que, aún desarrolladas desde la escuela, desborden este ámbito (Cantero \& Celman, 1998; Cantero, 2015).

Volviendo a las aulas, es necesario identificar contenidos a enseñar que son críticos para mitigar las desigualdades de capitales escolares y culturales de origen, no sólo en pos de una mayor igualdad, sino como nos menciona el maestro Paulo, para que los grupos oprimidos estén mejor formados para transformar sus realidades (Freire, 2010b). Entre estos contenidos estarían, por ejemplo, las herramientas de trabajo intelectual (Bourdieu \& Gros, 1990), que se dan por compartidas por todos los grupos sociales y en su mayoría no es así. Buscaríamos así recuperar el principio de justicia curricular como guía de las prácticas escolares (Connell, 1997), lo cual implica actuar en favor de los intereses de los grupos subalternizados, promoviendo en este proceso una participación y escolarización común y teniendo como horizonte una producción histórica de igualdad.

La experiencia de Paulo Freire al frente de la Secretaría de Educación del municipio de San Pablo (1989-1992) ha constituido una fuente inagotable para la construcción de saberes, que pudo ser reflexionada, sistematizada y tomada como inspiración para otras gestiones populares de la educación (Saul \& Gouvêa Silva, 2009; Saul, 2012). Estas gestiones tuvieron como principio rector la democratización de la escuela, en torno a: (1) construcción colectiva, (2) valorización de la autonomía de los centros educativos, (3) permanente trabajo de acción-reflexión-acción, (4) formación permanente de profesionales de la enseñanza. En cuanto al punto 3, se refiere a sucesivos ciclos de práctica educativa, análisis de la práctica y de transformación de la práctica a través de las conclusiones del último paso, pero también a una construcción metodológica para el trabajo con las y los estudiantes que implica tres momentos: el primero, de problematización inicial sobre una situación local; luego de organización de los contenidos, es decir, de labor sobre conceptos abstractos necesarios para abordar dicha problemática $\mathrm{y}$, finalmente, de aplicación de conocimiento, momento en el que se estudia de manera sistemática la situación y se abren miradas a partir de los conceptos mencionados previamente (Gehlen et al., 2009; Defago \& Ithuralde, 2018a). Estas situaciones, entendidas como temas generadores, son definidas a partir de la investigación temática propuesta por Paulo Freire (Delizoicov, 2008), buscando un diálogo de conocimientos cuyos portadores son los sujetos, estudiantes y docentes. Esta investigación temática en la formulación freiriana se realiza previo a estos tres 
momentos presentados, en la que se construyen las temáticas a trabajar en ellos (Freire, 2014b). El objetivo no es solamente producir una mirada crítica de estas situaciones o problemáticas, sino, ante todo, que dichos conocimientos sean instrumentos para una concientización, para la comprensión que posibilite transformar estas situaciones significativas para estudiantes y comunidad. Así, la contextualización es entendida, no como la ejemplificación de lo cotidiano, sino como la labor sobre una situación existencial crítica y significativa para los sujetos (Aparecida Aires \& Lambach, 2010).

Es necesario también en las clases de Ciencias Naturales desnaturalizar al conocimiento científico que, en tanto producto de la actividad social y humana, está cargado de intereses, subjetividad, ideología, y por lo tanto, pasible de sesgado, por lo que se vuelve fundamental una revisión crítica de sus prácticas y sus productos (Epoglou, 2019). Sostenemos que dicha reflexión crítica acerca del conocimiento científico no es solo una reflexión al interior mismo de la actividad científica, sino que debe formar parte de una alfabetización científica común, de la que la escuela secundaria debe ser agente promotor. La educación común y obligatoria debe poner al servicio del conjunto de la población, los conocimientos construidos y los modos de construirlos, de modo que esa producción científica y tecnológica pueda ser comprendida y valorada socialmente en todos sus alcances. Es decir, el acceso a la información que permita compartir estos saberes comunes, es lo que posibilita la construcción de una ciudadanía plena y garantiza la democratización sobre los usos y alcances del conocimiento científico en aquellos temas de relevancia social que no deben quedar reservados a la tecnocracia. De modo que sostenemos el derecho de los sectores populares al acceso a la cultura científicotecnológica como parte constituyente del panorama cultural de nuestro tiempo. Por ello, el cuestionamiento del que hablamos no es al derecho de los sectores populares al acceso a la cultura científica, sino que la labor es promover una problematización de la mirada hegemónica de ésta como inalcanzable, no pasible de ser cuestionada por personas de fuera del campo académico (desposeídas así de saberes) y posible de ser realizada sólo por unas pocas personas consideradas especialmente "inteligentes". La reflexión crítica se dirige a la desnaturalización de su neutralidad e incontestabilidad, a develar esa mirada hegemónica que deslegitima los saberes de los sectores populares y su experiencia, pero también de las y los trabajadores de la educación. Esta perspectiva requiere, como mencionamos previamente, de una labor colectiva para la investigación temática y la selección de temas generadores, así como para la producción de proyectos interdisciplinarios. La producción por parte de los docentes de tales proyectos deja pendiente la discusión y el interrogante acerca de las condiciones institucionales necesarias para poder construir, en cada escuela y de manera contextualizada, los temas generadores, como parte de un trabajo colectivo desde la educación popular (Delizoicov, 2008).

A través de la investigación que presentamos en el presente trabajo, buscamos identificar elementos clave y estrategias privilegiadas para posibilitar dicha construcción. Hemos trabajado haciendo observaciones en clases de educación secundaria de ciencias 
naturales que reconocemos se inscriben dentro de una perspectiva freiriana. Al mismo tiempo, hemos analizado dichas experiencias en diálogo con los mencionados diseños curriculares que prescriben los contenidos a ser enseñados y también con las orientaciones didácticas sobre cómo deberían ser enseñados según el enfoque que se plantea en los mismos diseños.

\section{Metodología}

Presentamos en este apartado algunas consideraciones metodológicas acerca de la investigación que hemos desarrollado. Se trata de una investigación cualitativa, realizada con un enfoque interpretativo crítico (Carr \& Kemmis, 1988). Forma parte de una indagación en torno a las prácticas de enseñanza de las materias de ciencias naturales en escuelas secundarias de la provincia de Buenos Aires. En este trabajo, nos focalizamos en aquellas prácticas que podemos clasificar dentro de una perspectiva de educación popular freiriana.

Se realizaron observaciones participantes en centros educativos del conurbano bonaerense, que permitieron un doble relevamiento: de manera contextual y con las y los actores. Esta estrategia estuvo destinada fundamentalmente a entablar un diálogo que permitiera conocer la voz de los protagonistas y comprender sus prácticas frente a los procesos de implementación del curriculum en los diversos espacios de actuación. Las observaciones realizadas en escuelas consistieron en acompañar las clases de una de las materias de ciencias naturales de la Educación Secundaria Orientada $\left(4^{\circ}\right.$ a $6^{\circ}$ año, materias: Introducción a la Química $\left(4^{\circ}\right.$ año de la orientación Ciencias Naturales y $5^{\circ}$ de las demás orientaciones), Fundamentos de Química ( $5^{\circ}$ año de la orientación Ciencias Naturales) y Ambiente, Desarrollo y Sociedad ( $6^{\circ}$ año de la orientación Ciencias Naturales). Se realizaron observaciones en 8 cursos diferentes de 5 instituciones en el partido de Quilmes, ubicado en el Gran Buenos Aires. Previo al trabajo de campo, los objetivos de la investigación fueron presentados de forma oral primero al personal directivo de la institución y luego al personal docente a cargo de los cursos observados y se informó acerca de los recaudos para conservar el anonimato. Se tomó registro de las observaciones en cuadernos de campo, ampliando las notas en días posteriores a partir de sucesivas relecturas de las mismas y de las aportaciones de las y los diversos actores.

Buscando desarrollar una generación conceptual, se recurrió al análisis de contenido como perspectiva para el análisis de datos (Bardin, 1977). Se pre-analizó inicialmente la información recogida recurriendo a la atención flotante como herramienta, releyendo los documentos, los registros de campo, las notas de las entrevistas, escuchando los audios y leyendo las transcripciones de las entrevistas. A partir de esta etapa de pre-análisis, construimos las dimensiones para el análisis de la información. Dichas dimensiones se utilizaron para organizar los datos construidos, que fueron sometidos a diversas rondas de análisis, en espiral, en las cuales se fue articulando teoría y experiencia. Los datos se fueron categorizando en torno a: los objetivos de la formación en ciencias, el diálogo en las clases de ciencias naturales, la justicia curricular y el trabajo de descolonizar la ciencia escolar. 
Para la labor de reflexión teórica que con este trabajo proponíamos, la primera tarea consistió en identificar, a partir de las observaciones, aquellos cursos en los que se desarrollaban prácticas que reconocemos se acercan a la perspectiva de educación popular freiriana. Sobre dichos cursos realizamos el resto de la investigación. Recurrimos no sólo a las memorias, registros y sistematizaciones anteriormente mencionadas, sino también a documentos de movimientos sociales latinoamericanos que trabajan sobre la educación y a indagaciones producidas desde las pedagogías críticas, que nos permiten ampliar nuestra mirada y profundizar el análisis. En este proceso, triangulamos los datos construidos a partir de las entrevistas, las observaciones participantes, información documental (con foco en los Diseños Curriculares de la provincia de Buenos Aires) y las conclusiones de anteriores trabajos sobre la Educación Popular y la Educación en Ciencias Naturales.

Iniciamos este trabajo, sobre todo, a partir de las preocupaciones compartidas en relación con la tarea de acercar las ciencias a los procesos de educación de los sectores populares. En esa búsqueda de integración, a partir de la reflexión sobre nuestra propia práctica, resultaron inspiradoras las palabras de Don Paulo Freire. En su reflexión sobre su experiencia como Secretario de Educación de la ciudad de San Pablo, advirtió sobre los problemas que se encuentran, al interior de los sistemas educativos para extender prácticas de educación popular. Nos reconocemos deudores de ese legado

\section{Resultados}

Los resultados que se presentan en los párrafos siguientes se estructuran a partir de los siguientes ejes: en primer lugar, narramos dos escenas que iluminan la construcción conceptual que compartimos en este trabajo. En segundo lugar, retomamos los ejes construidos a partir de nuestro trabajo de reflexión: (1) ¿Por qué una formación en ciencias?, (2) El diálogo, (3) Hacia una justicia curricular, (4) Descolonizar la ciencia escolar.

\section{Dos días en clases de ciencias}

\section{Primera escena: Química del Agua}

Clase de la materia Fundamentos de Química. $5^{\circ}$ año de la Escuela Secundaria Orientada. Escuela del Conurbano bonaerense, en el centro de una ciudad, a la que asisten estudiantes de todo el municipio, en general de sectores socioeconómicos medio bajos. La docente a cargo del curso, participa de experiencias de Educación Popular sostenidas por movimientos sociales.

Comienza la clase. Hay unos 30 estudiantes divididos en 6 grupos. Los bancos están dispuestos en estos 6 grupos. La docente comenta que les repartirá una noticia para que analicen y que puedan identificar qué tipo de contaminaciones existen en el agua según se plantea en la noticia. Un estudiante pregunta si pueden tener su carpeta 
abierta. La docente responde que sí y empieza a pasar por los bancos, dejando fotocopias de noticias acerca de diversos casos de contaminación de aguas. Son 3 noticias diferentes (cada noticia le toca a dos grupos): una sobre un pedido de rescisión de una concesión de distribución de agua potable donde se ha detectado la presencia de nitratos a concentraciones superiores a las permitidas; una nota sobre la proliferación de algas en un lago que se utiliza para fines recreativos y la obtención de agua potable y la última sobre la contaminación de aguas de un río con residuos de una curtiembre (metales pesados y materia orgánica). Cada nota de diario incluye además una guía de lectura, con referencias al trabajo previo realizado por todo el curso sobre concentraciones, química del agua y el agua potable, y una problematización de la situación ambiental de cada caso expuesto y la consigna de trabajo acerca de cuáles son los sectores más afectados por estas situaciones de contaminación.

En las carpetas de las y los estudiantes hay registros previos que permiten concluir que han venido trabajando sobre concentraciones en soluciones. Las carpetas contienen problemas de situaciones reales con pasajes de unidades y cálculos de concentración. Se trata de situaciones de la vida cotidiana como la preparación de una dilución de lavandina a partir de una solución de hipoclorito concentrado (cloro). También han trabajado sobre el Código Alimentario Argentino y la definición de agua potable, concentraciones máximas y mínimas permitidas, tanto de especies químicas como de bacterias y parásitos (que podría dar lugar a contaminación química, bacteriológica y parasitológica).

Volviendo a la tarea de la clase, cada grupo va leyendo y la docente los va recorriendo, respondiendo dudas y buscando que se profundice en el trabajo (con mayores precisiones sobre las consignas, con otros interrogantes, con indicaciones de volver sobre algún trabajo anterior particular, con algún ejemplo o contraejemplo para pensar). Cada grupo va produciendo un afiche con las respuestas a las preguntas guías y dando cuenta de qué tipo de contaminación - de las trabajadas anteriormente en clasepresenta el caso asignado (con alguna fundamentación).

La docente va preguntando por el tiempo que falta para concluir, vuelve a pasar brevemente por los grupos y finalmente pregunta qué grupo va a empezar la exposición. Como nadie quiere comenzar realiza un "sorteo" (a partir de números elegidos por tres estudiantes) y aclara que, a partir de allí, seguirán exponiendo por orden hacia la izquierda.

Los grupos van pasando y contando el afiche. Ante discordancias entre los grupos con la misma noticia, la docente pregunta al plenario qué les parece lo que dice este grupo, si el otro había sostenido otra cosa y coordina un debate.

Finalmente, vuelven sobre los tres tipos de contaminación escritos en el pizarrón y pregunta a qué tipo corresponde cada caso y anota las respuestas, precisando sucesivamente la definición hasta llegar a una síntesis. Por último, dice que la próxima clase tendrán una evaluación, que consistirá en resolver un problema de forma individual a carpeta abierta. Toca el timbre. Las y los estudiantes se levantan rápidamente y van al recreo (Cuaderno de campo, 2014). 


\section{Segunda escena: Agua, Contaminación, Ambiente y Sociedad a partir de mapeos sociales del propio territorio}

Es una materia de Ambiente, Desarrollo y Sociedad de $6^{\circ}$ (y último) año de la Escuela Secundaria Orientada en Ciencias Naturales. Escuela del Conurbano bonaerense, en el centro de una ciudad, a la que asisten estudiantes de todo el partido, en general de sectores socioeconómicos medio bajos. La clase está coordinada por un estudiante de profesorado que está realizando sus prácticas (y que realizó observaciones previas en el curso en cuestión). La docente titular observa lo que sucede.

El docente residente llevó mapas de una escala y tamaño adecuados (A3) y muchas hojas de calcar para el trabajo en grupos. Los mapas se desplegaron en las mesas de los grupos, y los estudiantes se sentaron alrededor del mismo, para posibilitar que todos participen. Los mapas habían sido descargados de la página del Instituto Geográfico Nacional (https://mapa.ign.gob.ar/). El docente residente orienta la ubicación de señales en el mapa, mediante preguntas y promoviendo el interés por distintas problemáticas, los actores que participan y el riesgo que implican para la población. Cada grupo construye distintos mapas en las hojas de calcar. Cada uno señaliza distintas categorías: los conflictos ambientales en el territorio, las relaciones comunitarias que se entretejen en torno a ellos (y los actores sociales que participan) y otro que representa conflictos, riesgos y potencialidades.

Los estudiantes van señalizando en su mapa industrias, zonas de vuelco de basura o basurales, depósitos visibles de sustancias tóxicas, escuelas, hospitales y centros de salud, etc. La cuenca que han elegido es cercana a los domicilios de los estudiantes, por lo cual construyen el mapeo a partir de su experiencia. Usan también unas viejas guías T que incluyen localizaciones de las industrias más importantes, y son así un buen complemento de los mapas del Instituto Geográfico Nacional.

La actividad parece ser bien recibida, y logran identificar algunos conflictos sociales debido a diferentes usos y valoraciones de la cuenca (entre vecinos de la misma y las industrias, por ejemplo).

Al terminar cada grupo le pasan sus mapas al grupo de al lado para que (con otro color) complete los mapas realizados desde su propia perspectiva. Las y los estudiantes se van gritando "te olvidaste de ..., "falta...".

Al terminar, el docente pregunta qué curso de agua han elegido y qué barrio. Anota en el pizarrón. Debajo (para cada curso y barrio) pregunta: qué actividades contaminantes encontraron, qué efectos tiene esa contaminación sobre las poblaciones, qué actores están presentes en ese territorio, qué sectores socioeconómicos viven en las cercanías de las zonas contaminadas, qué conflictos sociales existen. El docente va completando un cuadro de doble entrada en el pizarrón (en columnas, cada grupo/ cuenca y en las filas las anteriores dimensiones). Al terminar, le saca una foto al cuadro con su celular y dice que la próxima clase, lo compartirá, una vez pasado en limpio. 
Anota una frase en el pizarrón: ¿qué podemos hacer para transformar esta realidad? Comenta que a lo largo de las clases irán produciendo en cada grupo formas de estudiar la contaminación y de proponer acciones para resolver las causas o al menos mitigarlas. Y señala que, aunque las actividades contaminantes son diversas y que han mapeado cursos de agua en todo el partido, la respuesta a “iqué sectores socioeconómicos viven en las cercanías de la contaminación?" siempre ha sido la misma: sectores de bajos recursos. Suena el timbre. Dice que antes de irse escuchen y avisa que la próxima clase trabajarán sobre estos dos aspectos y que traten de sacar fotos de esos cursos de agua y de los barrios cercanos, para mostrar al resto. También les dice que luego harán entrevistas a gente que vive allí (Cuaderno de campo, 2015).

Estas escenas que mostramos dan cuenta de prácticas subalternas en clases de Ciencias Naturales de la Educación Secundaria en la provincia de Buenos Aires que "leen" los Diseños Curriculares desde una perspectiva pedagógica crítica. Una lectura que los Diseños Curriculares habilitan, al concebir a las ciencias como actividad humana contextualizada social e históricamente y a la enseñanza como actividad comprometida con la transformación del mundo (DGCyE, 2010b, 2011 y 2012). Es una interpretación que podemos postular en perspectiva freiriana de estos documentos, que busca justamente problematizar la realidad cotidiana del estudiantado, brindar herramientas para analizar su mundo. En este sentido, sostenemos que en esta perspectiva la Alfabetización Científica y Tecnológica puede comprenderse como una lectura del mundo y no sólo de la palabra.

Pero además fue posible porque existe un posicionamiento desde la Ley de Educación Provincial N 13.688 (Buenos Aires, 2007) y el Marco General de Política Curricular de la provincia de Buenos Aires (DGCyE, 2007) en el que las instituciones tienen como función, realizar estos procesos de especificación, que contextualice el curriculum en la práctica. Según este último documento:

Los diseños y propuestas curriculares - en tanto establecen intenciones, marcan una dirección - limitan; pero al hacer explícitos los fundamentos de cada una de sus decisiones habilitan y establecen un nuevo lugar para la profesionalidad del docente.

Toda prescripción curricular se recrea en su proceso de especificación. En la toma de decisiones vinculadas a la planificación y desarrollo didáctico, el/la docente define los sentidos específicos de su práctica en el marco de un contexto institucional y comunitario y de un grupo de alumnos/as particular. En este proceso, asume una postura teórico-epistemológica y política al constituirse en autor/a creativo/a de alternativas de enseñanza. 
Este modo de comprender los diseños y propuestas, además, posibilita a toda la comunidad - incluso a los/as docentes - el ejercicio de la demanda crítica al Estado por el mejoramiento de las condiciones institucionales que permitan el desarrollo profesional de la enseñanza como producción autónoma de proyectos y estrategias apropiadas a los contextos, grupos y sujetos. (DGCyE, 2007, p. 33).

Es decir, se da lugar explícitamente desde la normativa, a la autonomía de los centros educativos y de cada docente, para la interpretación de los diseños en función de las características particulares de las instituciones y sus comunidades. En este marco, hay una habilitación de la normativa hacia estas prácticas con visos de educación popular en las escuelas, recuperando los contenidos prescriptos de forma crítica y dialógica. Pero a diferencia de las experiencias relatadas en Brasil, no hay estrategias que fomenten una acción colectiva en las escuelas, el desarrollo de investigaciones temáticas y proyectos interdisciplinares conjuntos entre varias materias. Esta es una de las tareas pendientes para la construcción de alternativas y materiales curriculares orientados en clave de educación popular que resulta necesario profundizar.

En los apartados que siguen retomaremos postulados de los Diseños Curriculares, acompañados de las perspectivas de Ciencia Escolar (Izquierdo, 1997) y de Ciencia, Tecnología, Sociedad y Ambiente (Acevedo Díaz et al., 2002) que son abordadas por estos diseños, y realizaremos cruces con la Educación Popular freiriana, pensando cómo procesos de especificación curricular, en sus niveles más concretos, pueden recrear en las aulas los contenidos de los Diseños Curriculares desarrollados contextualizadamente de forma crítica, problematizadora $y$, cuando se plantea fortalecer vínculos con la comunidad, al menos con un viso emancipador.

\section{¿Para qué es la formación en ciencias?}

La segunda escena descripta muestra cómo a través de una actividad de mapeo escolar se reconocen problemáticas y conflictos sentidos por el estudiantado, se los reconceptualiza en función de un trabajo con una serie de contenidos escolares y se reflexiona sobre la posibilidad de transformación de los mismos. Es decir, la Educación en Ciencias Naturales tiene una direccionalidad (política) (Freire, 2014c), un claro posicionamiento en pos de problematizar situaciones injustas vividas por el estudiantado y mostrar que no son inexorables, estáticas ni inmutables, sino que podemos imaginar y crear vías para su transformación. El docente elige una temática y propone una estrategia para identificar dichas situaciones, pero son los y las estudiantes, grupalmente, quienes seleccionan dichas situaciones.

Toda la producción de Paulo Freire va en la dirección de pensar una educación emancipadora de las personas colonizadas (en sus primeros libros, pero también en Cartas a Guinea Bissau) u oprimidas (en su producción desde La educación como práctica de la libertad). Esta dirección de liberación es una guía para las prácticas educativas: en la construcción curricular, la enseñanza, la gestión educativa. Esta liberación es una construcción que no puede ser sino colectiva en la perspectiva freiriana y que instala la necesidad de la construcción de un "inédito viable" que sea capaz de dar forma y contenido a la transformación necesaria. 
En este sentido, nos parece necesario retomar y profundizar la pregunta acerca de por qué enseñar ciencias naturales en la educación secundaria común y obligatoria. Es decir, qué saberes se consideran pertinentes, relevantes, actualizados y necesarios para que una persona complete su socialización, se convierta en un miembro pleno de la comunidad, sea capaz de comprender y transformar su cotidianeidad. La pregunta contiene ya un posicionamiento que puede leerse en perspectiva freireana. Paulo Freire (2010) aborda en Educación en la ciudad el por qué enseñar el patrón culto del idioma portugués: se debe no sólo a que las y los estudiantes tienen derecho a conocerlo, sino que conociéndolo tendrán una mejor preparación para poder transformar su realidad. Ana Dumrauf et al. (2008) trabajan este tema señalando que es necesario que la Educación en Ciencias Naturales aborde las desigualdades e injusticias sociales como parte de la enseñanza, que pueda problematizarlas y generar situaciones en las que se pueda vislumbrar la posibilidad de una situación diferente (retomando la noción de inédito viable freiriano (Freire, 2014b) y pensar, a partir de allí, acciones colectivas para la transformación.

Desde una lectura crítica de la alfabetización científica y tecnológica (Dumrauf, 2006; Fourez, 1997), se propone una educación científica que no sólo trabaje sobre el lenguaje de la ciencia, sino que también fomente debates epistemológicos, aborde la aparente neutralidad de la actividad científica (en tanto mecanismo de legitimación de discursos y prácticas sociales) y las desigualdades que se avizoran como efectos sociales, al menos parcial, del desarrollo de la ciencia y la tecnología en las actuales condiciones (DGCyE, 2012).

Los Diseños Curriculares (DGCyE 2010b, 2011 y 2012) recuperaron la noción de Ciencia Escolar (Izquierdo, 1997), entendiendo que ésta

no es la ciencia de los científicos, sino una versión elaborada para su aprendizaje en los ámbitos escolares. El camino a recorrer será, entonces, desde los saberes de los estudiantes, hacia la comprensión y la interpretación de los modelos y teorías científicas. La ciencia, tal como el estudiante la reconstruye durante la escolaridad, es un puente entre el conocimiento cotidiano con el que se enfrenta habitualmente al mundo y los modelos y marcos teóricos desde los que los científicos interpretan y analizan los fenómenos naturales. En este sentido, la finalidad de la escuela no es la de formar científicos, sino ciudadanos que deben tener acceso a información actualizada y posibilidades de seguir aprendiendo (DGCyE, 2011, p. 17).

Para atender al carácter emancipador de la Educación Popular, postulamos aquí que las/os docentes, al interpretar los Diseños Curriculares para desarrollar una práctica liberadora en las aulas, podrían recurrir a lo que denominamos Ciencia Escolar comunitaria, retomando experiencias populares de producción de conocimientos (véase por ejemplo Leyva \& Speed, 2008; Czernikier et al., 2018). Para esto, se torna necesario retomar problemáticas sociales reconocidas como propias por la comunidad (y los conflictos sociales involucrados), promoviendo el fortalecimiento de los vínculos 
escuela-comunidad, como Paulo Freire (1959) ya advirtiera en su primer libro. Los vínculos escuela-comunidad han mostrado ser una dimensión fundamental para promover aprendizajes desde gestiones escolares en condiciones adversas (Cantero \& Celman, 1998): en establecimientos con pobres condiciones edilicias, en espacios de alta vulnerabilización de los derechos de la población (al acceso a la salud, educación, trabajo, vivienda, de violencia institucional, etc.). Pero no se trata aquí solamente de fortalecer esos vínculos para promover los aprendizajes que se definen desde niveles centrales del sistema educativo, sino que esos vínculos deben servir también para: (a) poder seleccionar problemáticas a trabajar en las escuelas en conjunto con las comunidades, de forma de reflexionar sobre la realidad social de la población de manera situada. Es decir, llevar adelante procesos de investigación temática en sentido freiriano, que permitan identificar temas generadores; (b) promover la construcción de aprendizajes (en tanto prácticas y herramientas culturales (Rockwell, 2000) que, mediante una problematización y mayor comprensión de esas situaciones existenciales significativas reconocidas en el punto anterior, estén al servicio de la transformación social de esas realidades profundamente injustas; (c) como una dimensión de la democratización de la gestión educativa (Cantero \& Celman, 1998). La construcción de amplias comunidades de aprendizaje (Torres, 2004) es un excelente punto de llegada en el fortalecimiento de estos vínculos, incluyendo en estos procesos participativos los contenidos prescriptos en los Diseños Curriculares, tal como lo describe Wolf Michael-Roth (2002). De esta forma, en la escuela "todos los agentes, y no sólo los profesores, poseen un papel activo, dinámico, experimentando nuevas formas de aprender, de participar, de enseñar, de trabajar, de jugar y de festejar" (Freire, 1989: sr, traducción propia). La escuela (o al menos estas experiencias escolares) se vuelve así un espacio de democratización no sólo para la comunidad escolar (personal educativo, de apoyo y estudiantado), sino para un conjunto más amplio de la población.

En este sentido, el estudio de casos, el trabajo con problemáticas y el uso de mapeos de conflictos locales pueden ser fértiles herramientas para trabajar desde las aulas en estas perspectivas (DGCyE, 2012). Por ejemplo, se pueden estudiar casos paradigmáticos de conflictos ambientales en el país y el mundo, en los que se trabaje la desigual distribución de costes ecológicos (Leff, 2006) en este sistema, se pongan en tensión conceptos como progreso y desarrollo, se camine hacia una comprensión científica de los desequilibrios en la naturaleza y se promueva una reflexión sobre otras formas de habitar el territorio, incluyendo a la producción material y la apropiación de bienes de la naturaleza. La construcción de mapeos colectivos sobre una problemática comunitaria dada (que puede realizarse entre estudiantes, docentes y actores de la comunidad), como puede ser el uso, la captación, tratamiento y distribución del agua en un barrio, "identificando problemáticas que los estudiantes sienten como propias en su comunidad. De esta forma, la escuela aparece inserta dentro de la vida de la comunidad" (DGCyE, 2012, p. 165). Estos mapeos, ante la ausencia de un trabajo conjunto entre docentes de investigación temática (Freire, 2014b), son fértiles herramientas para 
terminar de refinar este proceso en el aula con el colectivo estudiantil. Es decir, a partir de una temática muy general (en nuestro caso las cuencas de agua), identificada como significativa a partir de la investigación temática (Freire, 2014b), estos mapeos permiten identificar conflictos ambientales, sanitarios y/o sociales concretos, donde existen controversias sociocientíficas sentidas por grupos de estudiantes, que bien pueden tomarse a modo de esas situaciones existencias significativas que hablábamos antes. Es así una estrategia para poder llevar a cabo la perspectiva freiriana en condiciones de ausencia de trabajo colectivo entre educadores, en la cual la investigación temática continúa en el trabajo en las aulas y terminan de precisarse las situaciones significativas dentro de esos temas generadores en este proceso áulico. Esta actividad habilita entonces a un espacio más democrático y a la identificación de los temas generadores en sentido freiriano en aquellas instituciones donde docentes de forma aislada desean realizar un trabajo educativo crítico, acercándose a la Educación Popular.

Desde los diseños curriculares de las diversas materias de Ciencias Naturales para la educación secundaria, se propicia que las y los docentes busquen en las aulas:

- "presentar situaciones reales contextualizadas que impliquen verdaderos desafíos para los estudiantes, que admitan varias soluciones o alternativas de solución;

- integrar variedad de estrategias (uso de instrumentos, recolección de datos experimentales, construcción de gráficos y esquemas, búsqueda de información de diversas fuentes, encuestas, entrevistas, foros de discusión, entre otras);

- fomentar el debate de ideas y la confrontación de diversas posiciones en el trabajo grupal durante el proceso de resolución de las situaciones planteadas;

- permitir que los estudiantes comprendan que los procedimientos involucrados en su resolución constituyen componentes fundamentales de la metodología científica en la búsqueda de respuestas a situaciones desconocidas. (DGCyE, 2012, p. 179).

Estas recomendaciones favorecen que se promueva, de manera sostenida y sistemática, entre las y los docentes, un trabajo de reflexión y planificación tendiente a promover aprendizajes significativos, cada vez más profundos y relevantes para las y los estudiantes y su comunidad de pertenencia. Aprendizajes que impliquen desafíos para la transformación de la propia realidad personal y social. Pero también, aprendizajes que impliquen una comprensión no solo de los contenidos de las ciencias, sino sobre la ciencia y sus formas de producir y validar conocimientos y sobre los impactos que las ciencias producen en la sociedad. Estos planteos curriculares, entendemos, habilitan a las y los docentes a desarrollar las tareas de enseñanza desde una lectura de Educación Popular tanto para la producción de sus planificaciones como guía de su práctica áulica. 


\section{Diálogo}

El diálogo es uno de los grandes conceptos trabajados en la obra de Paulo Freire, apareciendo ya en su primera obra Educación y Actualidad Brasilera (Freire, 1959). Diálogo como proceso democratizador, en tanto permite una creciente participación de las personas en las instituciones y organizaciones. Diálogo entre pares y entre docentes y estudiantes. Diálogo que se basa, fundamentalmente, en una concepción del otro como semejante, como persona que se concibe igual, en tanto sujeto de los mismos derechos. Es en este sentido, que se puede vislumbrar una postura eminentemente humanista en la pedagogía de Freire. Una pedagogía transformadora de la práctica docente, en tanto lo corre de su lugar de único y privilegiado poseedor del saber, hacia el de quien, contando con un saber académico y legitimado, es capaz de establecer una relación genuina y personal con las y los estudiantes, poniendo ese saber al servicio de un proceso de construcción grupal de comprensión del mundo. Esa situación de diálogo es ya una transformación del mundo, una transformación de la forma de situarse en él que posibilita la construcción de subjetividades que van ganando, progresivamente, autonomía.

Es en este sentido que el rol docente, al coordinar el trabajo en grupos, puede pensarse como el rol de coordinación de los círculos de cultura freirianos, en los que las personas participantes:

Se encuentran y reencuentran todos en el mismo mundo común y, de la coincidencia de las intenciones que los objetivan, surgen la comunicación, el diálogo que critica y promueve a los participantes del círculo. Así juntos recrean críticamente su mundo: lo que antes los absorbía, ahora lo pueden ver al revés. En el círculo de cultura, en rigor, no se enseña, se aprende con "reciprocidad de conciencias"; no hay profesor, sino un coordinador, que tiene por función dar las informaciones solicitadas por los respectivos participantes y propiciar condiciones favorables a la dinámica del grupo, reduciendo al mínimo su intervención directa en el curso del diálogo (Freire, 2014b, p. 14).

Esto es, se busca un diálogo creador, constructor de una renovada subjetividad, que (re)crea el mundo y, entonces, lo transforma. Es una recreación cultural y, si estamos en presencia de comunidades de aprendizaje en el sentido de Rosa María Torres (2004), del territorio. Porque al recrear el mundo, se producen procesos de reterritorialización (Haesbaert, 2004), como se muestran en los ejemplos que nos brinda Wolf MichaelRoth (2002), en los cuales a partir de una problemática sociocientífica, se construye un proceso comunitario de aprendizaje, indagación y reflexión sobre el propio territorio, en el que éste mismo es reconstruido. Esta problematización (Freire, 2010) transforma la relación de los sujetos con los territorios y, entonces, a los territorios.

Esto es lo contrario de lo que sucede en las clases tradicionales de ciencias, en las que sólo se busca que las y los estudiantes puedan hacer uso de modelos para resolver cálculos en problemas descontextualizados, nombrar compuestos sin relación con 
prácticas humanas (como en las clásicas clases de nomenclatura química en las que no se trabajan transformaciones de la materia asociadas a los compuestos nombrados, sino solo un ejercicio repetido y ocioso de memorización sin sentido). Otro tanto sucede cuando "complejas definiciones propias de las disciplinas se presentan sin mediación ninguna del lenguaje coloquial que manejan los estudiantes, obstaculizando la comprensión de los conceptos" (DGCyE, 2011, p. 104). Como dice Paulo Freire, en estas situaciones podemos ver cómo la "palabra repetida es monólogo de las conciencias que perdieron su identidad, aisladas, inmersas en la multitud anónima y sometidas a un destino que les es impuesto y que no son capaces de superar, con la decisión de un proyecto" (2014b, p. 23). Este modo tradicional de encarar la enseñanza en general y la educación en ciencias en particular, en el que el/la docente se considera poseedor del saber y por lo tanto, distinto del otro, estudiante, carente de ese saber, se logran efectos sociales opuestos a los declarados: "desinterés de los jóvenes por los contenidos y las prácticas científicas, escasa formación en ciencias, así como imposibilidad de relacionar o transferir los conocimientos científicos a la comprensión del mundo natural o tecnológico que los rodea" (DGCyE, 2011, p. 104).

En este sentido, la perspectiva que se sostiene en los diseños curriculares (DGCyE, 2010, 2011 y 2012), el/la docente debe promover que las y los estudiantes puedan construir una argumentación o narrativa, progresivamente más precisa sobre sus propios puntos de vista, sobre los mundos naturales y tecnológicos que los interpelan, a la vez que visibilizar la diversidad de miradas existentes en el curso y en otros grupos sociales diferentes a los del estudiantado. Esto implica construir un diálogo en el que la voz del estudiantado sea valorizada, donde se recupere y valorice la experiencia social del conjunto de las y los estudiantes y en la que la voz del docente ayude a reflexionar, posibilite la escucha atenta de las diversas miradas y ayude a construir una comunidad de prácticas sociales de aprendizaje. Recuperamos así la escucha atenta y la posición activa docente en pos de promover la autonomía del estudiantado (Freire, 2015), valorizando sus saberes y viabilizando el diálogo entre pares y entre estudiantes y docente a través de distintas estrategias. En palabras de Delia Lerner, al adoptar aunque sea provisoriamente una posición de neutralidad, se busca que los y las estudiantes deban argumentar en defensa de sus hipótesis, estrategias o puntos de vistas. Pero esto no implica un rol inactivo de su parte, sino que ayuda a que circule la palabra:

facilita la comunicación, incita a explicitar diferentes puntos de vista, hace notar las diferencias y las discrepancias, decide en qué orden se discutirán, pone en evidencia la suficiencia o insuficiencia de la información disponible, ayuda a definir conclusiones, recuerda datos o conclusiones previas pertinentes para la discusión, plantea contraejemplos, hace respetar las normas establecidas para la discusión... (Lerner, 1996, pp. 102-103).

Es necesario a la vez que las y los estudiantes aprendan el lenguaje de la ciencia escolar, que sientan que su forma de hablar y escribir no es desvalorizada por la escuela (Freire, 2010b; Lemke, 1997). Es sumamente importante promover una 
contextualización que posibilte a las y los estudiantes comprendan que el aprendizaje del lenguaje de la ciencia escolar, como forma de comunicarse con otras personas, tiene el sentido de construir una ciudadanía activa para la transformación social, y que esto no implica que deben abandonar sus propias formas de expresión en sus comunidades ni avergonzarse de ellas en las escuelas. Las y los docentes ejercen una importante labor en la generación de entornos y mediaciones entre la cultura estudiantil y la de la ciencia escolar y viceversa (Giroux, 1992; Dumaruf \& Menegaz, 2013), tejiendo puentes cuando estos procesos puedan resultar "difíciles", "imposibles", "incomprensibles". Al trabajar con grupos sociales distintos al propio, como en escuelas en espacios habitados por sectores populares, esto implica un importante ejercicio de descentramiento cultural (Cantero \& Celman, 1998). Descentramiento imprescindible pero que necesita además de un compromiso con el "sueño de justicia" (Freire, 2015, p. 129) para reducir la distancia que separa al personal docente de las condiciones de vida del estudiantado. Sueño de justicia que en la segunda escena descripta aparecería como esos cambios que proponen los y las estudiantes.

En ambas escenas se promueve además un diálogo entre los saberes del/de la docente (en ese triángulo de saberes disciplinares, técnicos de la educación y de su propia experiencia) y saberes de cada grupo de estudiantes (y sus familias). Pero también se promueven actividades de ciencia escolar vivencialmente significativas (Camino, 2021), en términos de su experiencia escolar y comunitaria, y no sólo significativas en términos ausubelianos en los que lo significativo es que los nuevos conceptos puedan relacionarse a conceptos inclusores previamente construidos por cada estudiante. Entonces no sería sólo un diálogo de saberes, sino también de vivires y de sentires en torno a esas problemáticas que se identifican en esta actividad (Merçon et al., 2014).

\section{Un trabajo educativo situado con un sentido de justicia curricular}

En Educación como práctica de la libertad (Freire, 2010a), plantea un anclaje de la práctica educativa en el Tercer Mundo (como lugar desde donde se piensa, escribe, debate. "La cabeza piensa donde los pies pisan" (Betto, sf: sr). Es decir, hay una necesidad de situar la educación y contextualizarla, pero a la vez ampliando la mirada. La educación situada promueve la contextualización sin atarse exclusivamente a lo local. Más bien propone, a partir del reconocimiento de la propia experiencia, las necesarias articulaciones con situaciones de otros contextos, con escalas de alcance progresivamente mayores (regionales, globales), ya que la problemática de la desigualdad y la opresión tiene esas escalas (Wallerstein, 1991).

Los Diseños Curriculares proponen ejes temáticos como estructurantes de la enseñanza de conceptos de la Química. Así, por ejemplo, a partir de tres ejes temáticos (Química y combustibles, Química y alimentación y Química en procesos industriales), a lo largo del $4^{\circ}$ año de la Educación Secundaria Orientada se propone trabajar sobre tres grandes núcleos conceptuales de forma recursiva: relación estructura/propiedades, estequiometría y equilibrio químico (DGCyE, 2010b). Este avance hacia una mayor 
relación entre teoría y práctica es importante, ya que sin ella "la teoría puede convertirse en palabrería y la práctica en activismo" (Freire, 2015, p. 24). Sin embargo, al no situar en el contexto vivencial del estudiantado la enseñanza de estos conceptos, difícilmente se promoverá una problematización de estos y entonces una transformación de los mismos. Se puede entonces seleccionar problemáticas sociocientíficas/conflictos dentro de los ejes temáticos propuestos en los Diseños Curriculares (Defago \& Ithuralde, 2018a), problemáticas/conflictos que deben proceder de una escucha previa del grupo, actuando entonces como los temas generadores de la perspectiva freiriana, tal como sucede en la segunda escena. Indagación que Freire (2010a y 2014b) plantea se realizaría en los círculos de cultura, que en esta propuesta deberían estar integrados por personas con diversidad de roles en las comunidades amplias de aprendizaje (Torres, 2004). Es importante que estas problemáticas/conflictos sean elegidos pensando en su capacidad para develar las llamadas "situaciones límite" y romper con su ahistoricismo. Traspasando estas situaciones límites, que inmovilizan a las personas en su situación de opresión, se encuentra el inédito viable freiriano, aquello que se veía fuera de las condiciones de posibilidad (y entonces reforzaba la situación límite) y que en este proceso pedagógico se visibiliza, se torna posible, viable, a través de la acción colectiva organizada (Freire, 2014b).

Planteamos así, en consonancia con la Concepción Metodológica Dialéctica de la Educación Popular (Jara, 1995) un esquema de trabajo práctica-teoría-práctica o acciónreflexión-acción (Defago \& Ithuralde, 2018a, 2018b), que permita ir de lo concreto, en el centro de los círculos concéntricos freirianos, hacia los temas generales en los bordes y de vuelta desde afuera hacia dentro. En esta vuelta a lo concreto, se ponen en juego esos contenidos abstractos provenientes de las disciplinas para operar sobre la realidad concreta presentada a través de esas problemáticas/conflictos seleccionadas/ os. Estudiarlos, analizarlos, construir estrategias para su transformación, es el desafío de una propuesta de educación liberadora.

Estamos así construyendo en la práctica docente, en el nivel de especificación curricular más concreto (Terigi, 1999), una propuesta de educación en ciencias naturales desde la justicia curricular (Connell, 1997), a partir de una posible vía de interpretación de los Diseños Curriculares. Es decir, una educación que:

1. responda a los intereses de los grupos históricamente subalternizados. De modo que recuperen su memoria histórica, sus luchas, los sufrimientos sociales que han atravesado, y visibilicen la situación de violencia y desigualdad en la que se encuentran históricamente, como una situación social contingente y no inamovible.

2. que se proponga la construcción de herramientas culturales para la participación democrática en la sociedad como un eje transversal del curriculum (en nuestro caso, del curriculum enseñado). Esto requiere que se propongan situaciones didácticas que fomenten el aprendizaje cooperativo (Travier Martí, 2003) no sólo entre estudiantes sino además entre estudiantes 
y diversos miembros de la comunidad de aprendizaje (Torres, 2004).

3. que se tenga como eje una producción de la igualdad, es decir, una formación para una ciudadanía activa en pos de una transformación social del sistema injusto en el que vivimos. Es decir, no sólo fomentar una conciencia crítica respecto de la realidad, sino también una conciencia organizativa (Movimento dos Trabalhadores Rurais Sem Terra, 1996).

En este sentido, desde el Marco General de Política Curricular de la provincia de Buenos Aires se propone para abordar la tensión entre la selección de contenidos comunes, en tanto herencia cultural que se desea transmitir, y el reconocimiento de la diversidad sociocultural característica de los grupos sobre los que se realiza este legado:

concebir un curriculum común que garantice que todos los alumnos/as del sistema educativo provincial accedan y se apropien de los conocimientos requeridos para participar activamente en la toma de decisiones en una sociedad democrática. Asimismo, conlleva la introducción en los diseños y propuestas curriculares de enfoques, contenidos, objetivos y estrategias que atiendan a los intereses y producciones culturales de los diferentes grupos sociales, poniendo especial énfasis en los menos favorecidos/as de la sociedad (DGCyE, 2007, p. 16).

Es decir, que se propone desde este Marco General un cruce entre la justicia cognitiva (Santos, 2009), la no imposición de marcos epistémicos hegemónicos, y la justicia curricular. Porque, como ya se ha visto en el pasado, los universalismos (re) producidos desde el sistema educativo han sido un mecanismo de generación y persistencia de las desigualdades, pero también lo ha sido la fragmentación del sistema educativo (Diker, 2007). Esto aparece entonces como una tensión dentro del sistema educativo, en el que, las y los docentes deben caminar por este fino hilo, que permita un diálogo entre lo que se considera "común" y la cultura y prácticas de los grupos sociales a los que pertenece el estudiantado, como nos indica el maestro Paulo en las palabras iniciales de este texto (Freire, 2014a).

En un mundo cada vez más marcado por la crisis civilizatoria debido a desigualdades sociales y desequilibrios ambientales crecientes, los conflictos por la apropiación social de la naturaleza se agudizan día a día. En este sentido, el trabajo sobre la justicia ambiental que incluye también "los derechos territoriales y culturales de los pueblos" (Leff, 2001, p. 26). Justicia ambiental que en muchos casos se articula con la justicia sanitaria (cruces que son una deuda teórica en el campo educativo (Sauvé, 2005). El mapeo de nuestra segunda escena será utilizado en clases subsiguientes para poner en debate justamente esas interconexiones entre el derecho al ambiente sano y el derecho a la salud, consagrados ambos en la Constitución Nacional de la Argentina.

Una cuestión de importancia mayor es que, como agentes estatales, las y los docentes muchas veces juegan, a veces sin advertirlo de forma consciente, un importante papel en conflictos sociales que sacuden a la comunidad.

Un primer ejemplo, sería la imagen de sí mismos que contribuye a construir cierta educación en ciencias tradicional, que: 
se definía mediante la enseñanza de unos pocos conceptos, principios y leyes de las disciplinas científicas. Esta orientación de la enseñanza, sin embargo, resulta insuficiente como preparación para los futuros científicos. Fundamentalmente, porque transmite una idea deformada y empobrecida de la actividad científica, al presentarla como algo ajeno e inaccesible al conjunto de la población (DGCyE, 2011, p. 104)

Asistimos así a efectos performativos de la Educación en general (Saint Martin \& Bourdieu, 1998) y de la Educación en Ciencias Naturales en particular, a una introyección de la ideología opresora sobre los y las oprimidas que en términos freirianos inmoviliza: le da mayor legitimidad a los discursos y capacidades ajenas, ayudando a trazar trayectorias sociales que sostienen al status quo.

Otro ejemplo, puede encontrarse en conflictos públicos de las comunidades, como por ejemplo en conflictos de tierra entre campesinos y campesinas y representantes del agronegocio (Urdampilleta et al., 2021). Allí, el posicionamiento docente en las aulas puede tomar partido, de forma más explícita o implícita, por uno u otro grupo, a veces a partir de legitimar posiciones en ciertas controversias sociocientíficas, como ser el uso de agrotóxicos y la salud (humana y de la naturaleza), o sobre quién tiene derecho a la tierra (si propietarios con papeles dudosos o poseedores ancestrales). También sobre la imagen de progreso o desarrollo: si se da una imagen de superioridad de la vida urbana y de clases medias o altas o se problematizan esas representaciones hegemónicas.

En la primera escena presentada en este artículo, desde contenidos muy tradicionales de la química, como son las concentraciones de diversos solutos en soluciones acuosas, la docente presenta de forma contextualizada estos contenidos y promueve una problematización respecto de sobre quiénes se descargan los costes ecológicos de las producciones. Esto hace a una cuestión central de la (re)producción de la desigualdad social en el sistema capitalista, pero sobre todo en espacios periféricos como América Latina. Hay una desigualdad en los retornos de capital de la producción, pero también en los de las externalidades de esas producciones (Leff, 2006). Si este caso lo pensamos en poblaciones junto a cursos de agua contaminados, notamos cómo se puede trabajar en las aulas de ciencias naturales ( $\mathrm{y}$ con contenidos en general presentes en todo Diseño Curricular), en torno a las situaciones límite freirianas, que podrían llevar a producir el inédito viable (ayudado, por ejemplo, con relatos de experiencias colectivas en situaciones semejantes, como organizaciones contra la megaminería o las que lograron órdenes judiciales para el saneamiento de la cuenca Matanza-Riachuelo en Argentina).

En la segunda escena observada, podemos advertir cómo se promueve la propia construcción conceptual y análisis de una problemática social, que problematiza la legitimidad y validez de la información científica disponible, (re)valorizando saberes locales y formas populares de producción de conocimientos.

Las escenas muestran entonces cómo el trabajo docente puede resignificar el concepto de contextualización. En los Diseños Curriculares la contextualización se 
acerca más a la ejemplificación a partir de casos generales, en mostrar posibles dominios de aplicación de los conceptos teóricos trabajados. Sin embargo, en las escenas, no sólo se contextualiza a través de ejes temáticos generales que sirven de marco, sino que se seleccionan situaciones locales conflictivas en lo social dentro de ese gran marco, para problematizarlas y comprenderlas mejor e incluso (re)pensar posibles cursos de acción para su transformación. Así, la escuela se involucra directamente en las desigualdades sociales vividas por el estudiantado, se implica en una lucha por la igualdad, profundizando esa impronta que habilitan los Diseños Curriculares, a esa contextualización. Observamos entonces cómo el trabajo creativo (y comprometido) del cuerpo docente, haciendo uso de su autonomía, puede salir del corset de una lectura lineal de los Diseños Curriculares y abrirse a las diferentes opciones que la normativa habilita, en busca de la igualdad y la emancipación.

\section{Desmitificar la ciencia, descolonizar el saber sobre la ciencia}

Enseñar ciencias en una perspectiva liberadora implica que es necesario promover también una reflexión sobre las formas de producción de conocimiento, sobre su naturaleza. La ciencia, como el cuerpo de conocimiento y la institución que conocemos en la actualidad, tiene un origen espacial (Europa occidental) y temporal (siglos XVI/ XVII) (Walsh, 2007). Este conocimiento que es producido socialmente, como actividad humana, no despojada de intereses (personales y corporativos), ideologías, emociones, visiones del mundo debe ser también motivo de reflexión y de democratización institucional en diversos aspectos: producción, circulación y acceso al conocimiento producido.

En este sentido, es necesario desnaturalizar que la ciencia académica es la única manera correcta de observar e interpretar el mundo (Lemke, 1997), sino que existen otras maneras de analizarlo de forma sistemática, desde otras cosmovisiones, no por ello menos valederas. La ciencia pierde su lugar como único saber universalmente válido, un saber reconocido como legítimo en todo el globo, mientras que los demás serían saberes de alcance local.

En otra clase observada, a la cual asistieron personas del barrio donde se encuentra la escuela, se realizó un mapeo de casos de cáncer en las cercanías de la estación transformadora de electricidad. Para ello, previamente, grupos de estudiantes debían preguntar en las manzanas del barrio donde vivían, si conocían casos de enfermos de cáncer en la misma (Cuaderno de campo, 2015). De esta forma, se podía graficar en el espacio la "concentración" de casos por manzana1. Los mapas construidos visualizaban que esta "concentración" disminuía a medida que se alejaban de la estación. Esto que podemos pensar como una práctica de epidemiología popular (Breilh, 2013), realizada por las personas afectadas, genera una evidencia de una problemática de salud para la cual la ciencia no tiene una explicación mecanicista y, por tanto, rechaza dicha relación causal. Hay aquí un conflicto entre dos formas de producción y validación del saber

1 En Argentina se refiere al espacio urbano rodeado de calles, generalmente rectangular. 
sobre la que cada grupo de estudiantes debe poder argumentar y en ese diálogo, dar cuenta de la utilidad de cada cuerpo para interpretar la realidad y operar sobre ella, generando así una práctica de interculturalidad en acto (Rodríguez Rueda, 2005).

En este sentido, retomamos los primeros escritos de Freire (véase por ejemplo los de 1959) sobre la necesidad de descolonizarnos, cuestión que aparece en los inicios de su carrera pero que retomará en sus Cartas a Guinea-Bisseau (1977) cuando reflexione sobre el carácter colonizador del lenguaje y la importancia de que el sistema educativo del nuevo país independiente se organice en torno a la lengua nativa y no el portugués como idioma para la comunicación y enseñanza. Así, las prácticas y saberes populares son revalorizadas y problematizadas en conjunto con el saber científico.

En los Diseños Curriculares de Ciencias Naturales, sostenemos:

Estas visiones idealizadas, simplistas, pero no siempre ingenuas de la ciencia, conllevan posturas acerca de cómo debe enseñársela en el contexto escolar:

- las clases de ciencias se basan en la transmisión de un conocimiento que se da como indiscutible;

- la función de la observación y la experimentación es la de ilustrar o comprobar las verdades explicadas en los textos o por el docente (DGCyE, 2012, p. 14).

Es decir, nos conducen a una enseñanza que toma una mirada inductivista de la ciencia (Hodson, 1994), realizando muchas veces una cantidad altísima de experiencias científicas no siempre bien diseñadas ni aprovechadas como forma de acercarse a la construcción del conocimiento científico, ya que no se recrean variadas situaciones en las que estas experiencias pueden ser analizadas, interpretadas, debatidas desde diferentes miradas para poder llegar a síntesis individuales y colectivas que impliquen la formulación de modelos. Se trata también, a la vez, de una sobreutilización y de una infrautilización de estas experiencias.

Se infravalora en esta perspectiva simplificadora el papel de la teoría en la construcción del conocimiento, no atendiendo a una relación dialéctica que hay en este proceso entre la teoría y la experiencia (social y colectiva en su sentido más amplio (Thompson, 1989). Las publicaciones científicas así ya no son una verdad incuestionable como se desprende del estereotipo de la ciencia como neutral y aséptica, ya que el entendimiento de la naturaleza que genera y construye está filtrado por las preguntas que se hacen desde ciertos marcos epistémico-teóricos, los intereses creados para producir interrogantes, ciertos climas e ideas de época, etc., es decir, también tienen sesgos que es necesario que sean abordados de manera crítica. De otra forma, consideraríamos siempre que el saber popular sólo es legítimo cuando coincide con los resultados de estas publicaciones, y no en que muchos saberes teñidos de la experiencia territorial pueden llegar a ser en ciertas ocasiones más exactos que los de las publicaciones científicas, como el caso de la epidemiología popular. En los Diseños Curriculares apelamos a una cita de Werner Heisenberg al respecto:

La ciencia no nos habla de la Naturaleza: nos ofrece respuestas a nuestras preguntas 
sobre la Naturaleza. Lo que observamos no es la Naturaleza en sí misma, sino la Naturaleza a través de nuestro método de preguntar. De hecho, la relación del hombre con la naturaleza a través de la ciencia ha ido variando a lo largo de la historia, en función de la concepción que tenía el hombre de sí mismo y de sus finalidades en el mundo (Heisenberg, 1985 en Martín Díaz, 2002, pp. 59-60).

Esto no significa que no reconozcamos el derecho de todas las personas al acceso a la cultura científica, sino que este proceso también debe tener una mirada crítica y no una apropiación lineal de este cuerpo de saber. Es así como la escuela y la ciencia escolar se volverían más humildes, si aceptaran también el carácter provisional de sus conocimientos, que tomen conciencia de su propio inacabamiento (Freire, 2015), tal como lo planteara Paulo Freire:

Para nosotros no hay sombra de duda en torno del derecho que tienen los niños de los sectores populares de ser informados, en función de sus niveles de edad, y formarse de acuerdo con el avance de la ciencia. Es indispensable, sin embargo, que la escuela volviéndose popular, reconozca y prestigie el saber de clase, "hecho de experiencia", con el que el niño llega a la escuela. Es necesario que la escuela respete y acate ciertos métodos populares de saber cosas, casi siempre o siempre fuera de los patrones científicos, pero que llevan al mismo resultado. Es necesario que la escuela, en la misma medida que va siendo más competente, se vaya volviendo más humilde. El conocimiento que se produce social e históricamente tiene historicidad. No hay conocimiento nuevo que, producido, se "presente" libre de ser superado. (Freire, 2010b, p. 53).

Una estrategia para desmitificar estas imágenes hegemónicas de la ciencia escolar es apelar al uso de narrativas sobre la producción histórica de teorías y modelos, evidenciando las limitaciones de cada una, los obstáculos materiales y epistemológicos para generar evidencia de éstas y los contextos sociales de construcción teórica (Revel Chion \& Adúriz Bravo, 2014). Pero no sólo de las imágenes de la ciencia escolar sino también sobre otros cuerpos de conocimientos (Ithuralde, 2020), sobre los que también se construyen mitos, muchas veces como mecanismo de subalternización de los mismos. Entendemos que es ésta la labor que propone Paulo Freire (2010a) y que queda expresada en esa frase con la que iniciamos este trabajo. Así, podríamos debatir cómo la "investigación científica se desarrolla, la mayor parte de las veces, en el marco de confrontaciones de intereses" (DGCyE, 2012, p. 16).

En la malla curricular de la orientación de Ciencias Naturales de la Escuela Secundaria Orientada de la provincia de Buenos Aires (DGCyE, 2012), se definió como una materia propia de esta orientación a Filosofía e Historia de la Ciencia y la Tecnología, entendiendo a ésta parte esencial de la formación científica escolar y de la formación docente. Es decir, que la formación y reflexión sobre la ciencia y la tecnología como actividad social se toma como parte indisociable de las Ciencias Naturales, como una dimensión de la producción de conocimiento sobre la naturaleza y la tecnología, 
en general invisibilizado y, además, muchas veces inferiorizado desde la comunidad académica. Esta materia se incluye en el último año de la Educación Secundaria junto a Ambiente, Desarrollo y Sociedad, las que

trascienden lo disciplinar ya que articulan saberes de distintos campos. (...) Estas materias permiten problematizar el campo de las ciencias naturales al aportar miradas críticas e integradoras de la práctica científica y su vinculación con problemáticas sociales, filosóficas y éticas (DGCyE, 2012, p. 23).

Pero estas discusiones no son propias de una materia (aunque en alguna se haga foco en ellas), sino que deberían recorrer transversalmente la Educación en Ciencias Naturales. En particular, en ambas escenas narradas al inicio de este artículo, se ponen en debate estas cuestiones, en particular en la segunda. Como continuación de la materia de la primera escena, se realizó posteriormente un "juicio al agua", donde los grupos de estudiantes debían ejercer una posición respecto a un conflicto ambiental en torno al uso y distribución del agua, donde se ponían en cuestión alternativas emanadas desde posturas como la "Química Verde" o la modernización ecológica respecto, por ejemplo, a las bondades de tratamientos de agua o la reducción de su uso (y por consiguiente de los volúmenes de líquido afectados por la contaminación). En este sentido, se pone de relieve el derecho de los pueblos a debatir y definir acerca de las diferentes formas de uso de un bien común (tan esencial como el agua para la vida entera, humana y no humana) y de las alternativas tecnológicas disponibles, decisiones que no necesariamente deben quedar en manos de personas "expertas", "técnicas", "profesionales". Recuperamos así el sentido reflexivo de la Educación Popular (Freire \& Faundez, 2014), su rol cuestionador y promotor de la curiosidad y la creatividad antes que el ofrecimiento de respuestas cerradas a preguntas vacías, articulando aquí también con las perspectivas críticas de la Alfabetización Científica y Tecnológica (Fourez, 1997) y el movimiento Ciencia, Tecnología, Sociedad y Ambiente (Acevedo Díaz et al., 2002).

\section{Conclusiones e Implicaciones}

Recuperar la obra y la práctica de Paulo Freire para pensar la Educación en Ciencias Naturales implica estructurar este pensamiento en base a conceptos nodales de su propuesta de Educación Popular: el compromiso político con los grupos subalternizados, el sentido emancipador de la práctica educativa, el diálogo (real, participativo y, ante todo, creador) como modo de comunicación genuina.

En la literatura académica se encuentran diversas reflexiones y sistematizaciones de experiencias en las que institucionalmente, o al menos un grupo de docentes, desarrollan una enseñanza de las Ciencias Naturales comprometida desde una perspectiva de la Educación Popular latinoamericana de base freiriana. En indagaciones previas apoyadas en el Movimiento de reorientación Curricular brasileño se describen experiencias de gestión educativa basadas en principios freirianos (Delizoicov, 2008; Saul \& Silva, 2009). En nuestro trabajo de campo, no hay una gestión educativa ni un diseño curricular 
freiriano, aunque el enfoque de ambas deja abierta la puerta para que docentes, en la autonomía de su trabajo encaren prácticas educativas desde una perspectiva freiriana en tanto se propone una enseñanza contextualizada de las Ciencias Naturales (en una mirada de ciencia escolar) en tanto actividad social y humana. Esta autonomía del trabajo docente cobra un papel primordial en este contexto para poder desarrollar en el proceso de especificación curricular (Terigi, 1999) una interpretación de los Diseños Curriculares en perspectiva freiriana. Un ejemplo claro es la resignificación de la contextualización que se realiza en las propuestas analizadas, donde este principio no es pensado sólo como una ejemplificación de contenidos disciplinares o como ámbitos de aplicación (tal como se trabaja en los Diseños Curriculares), sino que en dichos casos, los docentes retoman situaciones existenciales significativas que permiten la problematización de las mismas, de situaciones de desigualdad e inmovilidad y puedan abrir a imaginar ( $\mathrm{y}$ crear) un horizonte de transformación. En el ejemplo del trabajo de epidemiología popular vemos cómo se crean "las posibilidades de su producción o de su construcción [del conocimiento]" (Freire, 2015, p. 24), en particular de un conocimiento sistemático y popular que confronta con el de agentes académicos al servicio de una gran empresa eléctrica y con los intereses de ésta. De esta forma, la recuperación crítica y dialógica de los contenidos escolares prescriptos implicó, en las escenas y experiencias analizadas, situar a los mismos con un compromiso con la lucha contra las injusticias.

La ausencia de apoyo institucional a estas prácticas educativas comprometidas limita las potencialidades de dichas experiencias y su posibilidad de crecimiento dentro del sistema educativo, generando además diversos obstáculos como la necesidad de realizar numerosas tareas en soledad: construcción de material, realización de investigaciones temáticas, generación de vínculos con la comunidad, entre otros. Investigaciones previas han mostrado cómo la labor colectiva (y muchas veces con profesionales de apoyo) permite la realización de potentes investigaciones temáticas y de un trabajo interdisciplinario y problematizador. En este artículo mostramos formatos en que un/a único/a docente puede retomar en su curso esta perspectiva cuando no existen estas condiciones grupales e institucionales en su establecimiento. Ante la inexistencia de condiciones para realizar el proceso de investigación temática con anterioridad a la planificación e implementación de su propuesta pedagógica, hemos sistematizado herramientas que permiten realizarla como parte de la misma a partir de una temática muy general definida por el/la docente. Así, las situaciones existenciales significativas emergen en estas tareas realizadas por el estudiantado, individualmente, en grupos o en plenario.

Otra cuestión primordial es la construcción de vínculos más allá de la comunidad escolar (personal escolar y estudiantes), que abarquen a las familias y también más allá de ellas, a quienes habitan y construyen el territorio en que el espacio educativo se encuentra, como parte de estas propuestas pedagógicas. Los saberes de las familias, vecinos/as y otros/as actores/as comunitarios o barriales ingresan así en la escuela a partir de las indagaciones realizadas por estudiantes como parte de su tarea o como invitaciones 
a participar de estas labores escolares por parte de el/la docente, compartiendo así la experiencia y generando diálogos de saberes, vivires y sentires. (Merçon et al., 2014). Como decía Paulo Freire: "la educación no cambia al mundo, cambia a las personas que van a cambiar el mundo". Pero al pensar la acción territorial de las prácticas escolares, en su imbricación con las comunidades que habitan el espacio donde se enclava el establecimiento, se pueden realizar acciones desde la escuela en coordinación con organizaciones, movimientos y colectivos que están transformando esos territorios. La escuela, o al menos grupos organizados de docentes de ésta, se puede constituir, así como un actor dentro de este motor comunitario de cambio. Las propuestas que hemos mostrado a lo largo del artículo recuperan articulaciones interdisciplinares y con la Educación Ambiental y la Educación en Salud desde una perspectiva de la Educación Popular freiriana. En todos los casos hay una preocupación por la ética del cuidado de la vida (de vidas humanas y no humanas) que une a dos ámbitos de reflexión propiamente latinoamericanos como el Pensamiento Ambiental Latinoamericano (Corbetta, 2014) y la Salud Colectiva (Breilh, 2013). Ética del cuidado de la vida que va de la mano del pensamiento humanista de Paulo Freire (2015). Estos ámbitos de debate, que promueven diálogos entre saberes populares y saberes de la ciencia, en nuestro caso ciencia escolar, permiten complejizar la enseñanza en Ciencias Naturales, ampliar los dominios de aplicación de sus conceptos y problematizar una mayor diversidad de situaciones existenciales de manera integral, acercándonos así desde nuestro accionar en cada curso a la perspectiva freiriana.

En tiempos en quela pandemia de covid-19avanza por las barriadas y comunidades más desprotegidas, en que las desigualdades sanitarias, de género, socioeconómicas, geográficas, étnicas se intersectan y que desde sectores del poder se fomentan prácticas individualistas del "sálvese quien pueda" o el terror, retomar el camino de la promoción de la solidaridad social, apoyar la reconstrucción de prácticas colectivas de cuidado, problematizar las formas de acceso a la salud, aparece como una tarea fundamental de la educación (en cualquiera de sus áreas) desde la perspectiva de la Educación Popular. Es sobre estos pilares que debemos (y podemos) (re)pensar la Educación en Ciencias Naturales, retomando, como docentes, nuestro rol de intelectuales críticos y críticas (Freire, 2015). Una apuesta por la diversidad en un mundo de verdades únicas, como la que nos traen tanto la Salud Colectiva como el Pensamiento Ambiental Latinoamericano, una ética del cuidado de la vida.

\section{Agradecimientos}

Raúl Esteban Ithuralde es Investigador Asistente de CONICET. Agradece el financiamiento de la Universidad Nacional de Santiago del Estero a través de los proyectos PI UNSE 23/D203 y 23/D234 y de la Universidad Nacional de La Plata a través del proyecto de investigación H928. 


\section{Referencias bibliográficas}

Acevedo-Díaz, J. A., Vázquez Alonso, Á., \& Manassero Mas, M. A. (2002). El movimiento ciencia-tecnología-sociedad y la enseñanza de las ciencias. Sala de Lectura CTS $+I$.

Aparecida Aires, J., \& Lambach, M. (2010). Contextualização do ensino de Química pela problematização e alfabetização científica e tecnológica: uma possibilidade para a formação continuada de professores. Revista Brasileira de Pesquisa em Educação em Ciências, 10(1). https://periodicos.ufmg.br/index.php/rbpec/article/view/3984

Bardin, L. (1977). Análisis de Contenido (2 ed.). Akal.

Bourdieu, P., \& Gross, F. (1990). Principios para una reflexión sobre los contenidos de la enseñanza. Revista de Educación, 292, 417-425.

Bourdieu, P., \& Saint Martin, M. (1998). Las categorías del discurso profesoral. Propuesta Educativa, 9(19), 4-18.

Bourdieu, P. (2012). La Distinción: criterio y bases sociales del gusto. Taurus.

Bourdieu, P. (2014). Sobre el Estado: cursos en el Collège de France (1989-1992). Anagrama.

Breilh, J. (2013). La determinación social de la salud como herramienta de transformación hacia una nueva salud pública (salud colectiva). Revista de la Facultad Nacional de Salud Pública, 31(1), 13-27.

Camino, N. (2021). Diseño de actividades para una Didáctica de la Astronomía vivencialmente significativa. Góndola. Enseñanza y Aprendizaje de las Ciencias, 16(1), $15-37$.

Cantero, G. (2015). Prácticas de gobierno escolar como prácticas de educación popular en la escuela pública. En el horizonte de una educación pública y popular. Revista Polifonías, 4(7), 101-131.

Cantero, G., \& Celman, S. (1998). La gestión escolar en condiciones adversas (Informe Final Proyecto de Investigación, Facultad de Ciencias de la Educación, Universidad Nacional de Entre Ríos, Entre Ríos, Argentina).

Carr, W., \& Kemmis, S. (1988). Teoría crítica de la enseñanza: la investigación-acción en la formación del profesorado. Ediciones Martínez Roca.

Connell, R. (1997). Escuelas y justicia social. Morata.

Corbetta, S. (2015). Pensamiento ambiental latinoamericano y educación ambiental. Voces en el Fénix, 6(43), 152-159.

Cullen, C. (2009). Entrañas éticas de la identidad docente. La Crujía.

Czernikier, A., Ithuralde, R. E., \& Panal, M. (2018). Los bachilleratos populares del Movimiento Popular La Dignidad: espacios de construcción de poder territorial. Universidad y Sociedad, 10(4), 169-179. 
De Alba, A. (1998) Currículum: crisis, mito y perspectivas. Miño y Dávila.

Defago, A., \& Ithuralde, R. E. (2018a). El Diseño Curricular de Química del Ciclo Superior de la Educación Secundaria en la provincia de Buenos Aires, Argentina: una posible lectura para las aulas. Revista Eureka sobre Enseñanza y Divulgación de las Ciencias, 15(1), 1203. https://doi.org/10.25267/Rev_Eureka_ensen_divulg_cienc.2018. v15.i1.1203

Defago, A., \& Ithuralde, R. E. (2018b). Hacia una contextualización de la enseñanza de la Química: contenidos articulados en torno a problemáticas sociocientíficas como ejes temáticos. Boletim da Associação Ibero-Americana CTS, (8), 34-39.

Delizoicov, D. (2008). La Educación en Ciencias y la Perspectiva de Paulo Freire. Alexandria: Revista de Educação em Ciência e Tecnologia, 1(2), 37-62. https://periodicos. ufsc.br/index.php/alexandria/article/view/37486

DGCyE (2007). Marco general de política curricular. Niveles y modalidades del sistema educativo. http://servicios.abc.gov.ar/lainstitucion/organismos/consejogeneral/ disenioscurriculares/documentosdescarga/marcogeneral.pdf

DGCyE (2010a). Diseño Curricular para la Educación Secundaria: Marco General para el Ciclo Superior. http://servicios2.abc.gov.ar/lainstitucion/organismos/consejogeneral/ disenioscurriculares/secundaria/marco_general_ciclo\%20superior.pdf

DGCyE (2010b). Diseño Curricular para la Educación Secundaria: Orientación Ciencias Naturales $4^{\circ}$ año. https://abc.gob.ar/secundaria/sites/default/files/documentos/marco_ naturales_4.pdf

DGCyE (2011). Diseño Curricular para la Educación Secundaria: Orientación Ciencias Naturales $5^{\circ}$ año. https://abc.gob.ar/secundaria/sites/default/files/documentos/marco_ naturales.pdf

DGCyE (2012). Diseño Curricular para la Educación Secundaria: Orientación Ciencias Naturales $6^{\circ}$ año. https://abc.gob.ar/secundaria/sites/default/files/documentos/marco_ naturales_0.pdf

Diker, G. (2008). ¿Cómo se establece qué es lo común?. En G. Frigerio y G. Diker (Comps.) Educar: posiciones acerca de lo común (pp. 147-170). Del Estante Editorial.

Dumrauf, A., \& Menegaz, A. (2013). La construcción de un currículo intercultural a partir del diálogo de saberes: descripción y análisis de una experiencia de formación docente continua. Revista Electrónica de Enseñanza de las Ciencias, 12(1), 85-109. https://dialnet.unirioja.es/servlet/articulo? codigo $=5643227$

Dumrauf, A., Cordero, S., Mengascini, A., \& Mordeglia, C. (09-12 de septiembre, 2008). ¿Qué ciencias para qué mundo?. XXIII Encuentros de Didáctica de las Ciencias Experimentales. 
Dumrauf, A. (04-06 de octubre, 2006). La mirada de los otros: algunas preguntas y reflexiones para un debate necesario acerca de la educación en ciencias hoy. Memorias del $8^{\circ}$ Simposio de Investigadores en Educación en Física. Gualeguaychú, Argentina.

Epoglou, A., \& Ribeiro Marcondes, M. E. (2020). O ensino de ciências nos anos iniciais: contribuições da obra de Paulo Freire para ampliar perspectivas em um curso de formação continuada. Revista Electrónica de Enseñanza de las Ciencias, 19(1), 225-249. http://revistas.educacioneditora.net/index.php/REEC/article/view/447

Fourez, G. (1997). Alfabetización Científica y tecnológica. Ediciones Colihue.

Franco, T., \& Merhy, E. (2016). Trabajo, producción del cuidado y subjetividad en salud. Lugar Editorial.

Freire, P. (1959). Educação e atualidade brasileira (Tese de concurso para a Cadeira de História e Filosofia da Educação, Escola de Belas Artes de Pernambuco, Recife, Pernambuco). Acervo Paulo Freire. http://www.acervo.paulofreire.org:8080/jspui/ handle/7891/1976

Freire, P. (1989). Construindo a Educação Pública Popular. Informativo Unioeste. http:// acervo.paulofreire.org:8080/xmlui/handle/7891/4378

Freire, P. (2010a). La Educación como práctica de la libertad. Siglo XXI Editores.

Freire, P. (2010b). La educación en la ciudad. Siglo XXI Editores.

Freire, P. (2011). Cartas a Guinea Bisseau. Apuntes de una experiencia pedagógica en proceso. Siglo XXI Editores.

Freire, P. (2014a). Cartas a quien pretende enseñar. Siglo XXI Editores.

Freire, P. (2014b) Pedagogía del oprimido. Siglo XXI Editores.

Freire, P. (2014c). El grito manso. Siglo XXI Editores.

Freire, P. y Faundez, A. (2014) Por una pedagogía de la pregunta. Siglo XXI Editores.

Freire, P. (2015). Pedagogía de la Autonomía. Siglo XXI Editores.

Gehlen, S. T., Auth, M., \& Auler, D. (2008). Contribuições de Freire e Vygotsky no contexto de propostas curriculares para a Educação em Ciências. Revista Electrónica de Enseñanza de las Ciencias, 7(1), 63-85.

Giroux, H. (1992). Border crossings: cultural workers and the politics of education. Routledge.

Haesbaert, R. (2011). El mito de la desterritorialización. Siglo XXI.

Hodson, D. (1994). Hacia un enfoque más crítico del trabajo de laboratorio. Enseñanza de las ciencias, 12(3), 299-313. https://raco.cat/index.php/Ensenanza/article/view/21370 Ithuralde, R. E. (2020). Hacia una Educación Popular en ¿ciencias?. Cadernos de pesquisa, 50(175), 186-208. 
Izquierdo Aymerich, M. (2005). Hacia una teoría de los contenidos escolares. Enseñanza de las ciencias, 23(1), 111-122.

Izquierdo, M., Espinet, M., García, M. P., Pujol, R. M., \& Sanmartí, N. (1999). Caracterización y fundamentación de la ciencia escolar. Enseñanza de las ciencias, (número extra), 79-91.

Jara Holliday, O. (1995). Concepción Dialéctica de la Educación Popular. Revista Umiña 1 (mimeo).

Leff, E. (2001). Justicia Ambiental: Construcción y Defensa de los Nuevos Derechos Ambientales, Culturales y Colectivos en América Latina. PNUMA/CEIICH-UNAM.

Leff, E. (2006). La ecología política en América Latina: un campo en construcción. En H. Alimonda (comp.) Los tormentos de la materia. Aportes para una ecología política latinoamericana. Consejo Latinoamericano de Ciencias Sociales.

Lemke, J. (1997). Aprender a hablar ciencia. Ediciones Paidós.

Lerner, D. (1996). La enseñanza y el aprendizaje escolar: alegato contra una falsa oposición. En J. A. Castorina, E. Ferreiro, M. Kohl de Oliveira y D. Lerner. PiagetVigotski: contribuciones para replantear el debate. Paidós.

Ley de Educación Provincial N 13688 (2007). 5 de julio de 2007. D. O. N 1296/2007. http://servicios.abc.gov.ar/lainstitucion/sistemaeducativo/consulta2007/default.cfm

Leyva, X., \& Speed, S. (2008). Hacia la investigación descolonizada: nuestra experiencia de co-labor. En X. Leyva, A. Burguete, y S. Speed (comp.). Gobernar (en) la diversidad: experiencias indígenas desde América Latina. Hacia la investigación de co-labor (pp. 3459). CIESAS/FLACSO Ecuador y FLACSO Guatemala.

Martín Díaz, M. J. (2002). Enseñanza de las ciencias ¿Para qué?. Revista Electrónica de Enseñanza de las Ciencias, 1(2), 57-63. http://reec.uvigo.es/volumenes/volumen1/ REEC_1_2_1.pdf

Merçon, J., Núñez Madrazo, C., Camou-guerrero, A., \& Escalona-aguilar, M. Á. (2014). ¿Diálogo de saberes? La investigación acción participativa va más allá de lo que sabemos. Decisio, (38), 29-33.

Movimento dos Trabalhadores Rurais Sem Terra — MST (1996). Princípios da educação no MST. Caderno de Educação (no 8).

Revel Chion, A., \& Adúriz-Bravo, A. (2014). ¿Qué historias contar sobre la emergencia de enfermedades? El valor de la narrativa en la enseñanza de las ciencias. Tecné, Episteme y Didaxis: TED, 1(36), 47-60. http://dx.doi.org/10.17227/01213814.36ted47.59

Rockwell, E. (2000). La otra diversidad: historias múltiples de apropiación de la escritura. DiversCité Langues, 5. https://www.teluq.ca/diverscite/SecArtic/Arts/2000/rockwell/txt. htm 
Rodríguez Rueda, A. (sf). Lecciones de una didáctica comunitaria e intercultural de una enseñanza de las ciencias naturales y sociales en las escuelas indígenas del Cauca y el Amazonas (Colombia). Fundación Caminos de Identidad.

Rogoff, B. (1993). Aprendices del pensamiento. Paidós.

Roth, W. M. (2002). Aprender ciencias en y para la comunidad. Enseñanza de las ciencias, 20(2), 195-208. https://raco.cat/index.php/Ensenanza/article/view/21798

Santos, B. S. (2009). Una Epistemología del Sur. Siglo XXI Editores.

Saul, A. M., \& Silva, A. F. G. (2009). O legado de Paulo Freire para as políticas de currículo e para a formação de educadores no Brasil. Revista Brasileira de Estudos Pedagógicos, 90(224), 223-244.

Saul, A. M. (2012). O pensamento de Paulo Freire na Educação Brasileira: análise de sistemas de ensino a partir de 1990. Currículo sem Fronteiras, 12(3), 37-56.

Terigi, F. (1999). Curriculum: itinerarios para aprehender un territorio. Santillana.

Thompson, E. P. (1992). Folklore, antropología e historia social. Revista de Historia, 2, 63-86.

Traver Martí, J. A. (2003). Aprendizaje cooperativo y educación intercultural. En A. Sales. Educació intercultural: la diversitat cultural a l'escola. Universitat Jaume I.

Torres, R. M. (5-6 de octubre, 2001). Comunidad de Aprendizaje. Repensando lo educativo desde lo educacional y el desarrollo local. Simposio Internacional sobre Comunidades de Aprendizaje.

Urdampilleta, C. M., Totino, M., \& Ithuralde, R. E. (2021). La educación como espacio en disputa entre el campesinado y el agronegocio. Praxis \& Saber, 12(29), e11439.

Wallerstein, I. (1990). World-Systems Analysis: the second phase. Review, 13(2), 287293.

Walsh, C. (2007). ¿'Son posibles unas ciencias sociales/culturales otras? Reflexiones en torno a las epistemologías decoloniales. Nómadas, (26), 102-113. 
Alejandra E. Defago

Universidad de Buenos Aires

Dirección General de Cultura y Educación, provincia de Buenos Aires

Buenos Aires, Argentina adefago@gmail.com

Raúl Esteban Ithuralde

Instituto de Estudios para el Desarrollo Social (Universidad Nacional de Santiago del Estero/CONICET) Universidad Nacional de La Plata Dirección General de Cultura y Educación, provincia de Buenos Aires Santiago del Estero, Argentina ithu19@gmail.com

Editora Responsable

Stefannie Ibraim

Manifesto de Atención a las Buenas Prácticas Científicas y de ausencia de conflicto de interés

Los autores declaran haber tenido cuidados éticos a lo largo del desarrollo de la investigación y no tener conflicto de interés o relaciones peronsales que puedan haber influenciado el trabajo que se relata en el texto. 